\title{
VeSTIBOLOGY
}

\section{Symptom improvement after transtympanic tube placement in Ménière's disease: preliminary observations}

\author{
Miglioramento dei sintomi con tubicino trans-timpanico nella malattia di Ménière: \\ osservazioni preliminari
}

\author{
Vincenzo Marcelli', Lucrezia Spadera¹, Erica De Bernardo¹, Giuseppe Barba¹, Eugenio Martino¹, Marcello Gentile², \\ Giuseppe Tortoriello ${ }^{1}$ \\ ${ }^{1}$ UOC ENT Ospedale del Mare, Naples, Italy; ${ }^{2}$ ENT Clinica Santa Patrizia, Naples, Italy
}

\section{SUMMARY}

Objective. The treatment of choice for Ménière disease (MD) aims at preventing severity and frequency of vertigo attacks. The purpose of this study was to evaluate the effectiveness of ventilation tube (VT) placement on vertigo control in patients affected by MD with no response to standard medical therapy.

Methods. 76 consecutive outpatients diagnosed with definite MD who failed medical therapy received VT insertion at the Department of Otolaryngology Head and Neck Surgery, "Ospedale del Mare", Naples, Italy, with a 3-year follow up.

Results. Over the long term, VT placement was effective in controlling vertigo in $61.8 \%$ of patients. In the control group treated with standard preventive care (SPC) alone, all patients continued to experience recurrent vertigo during the entire study. Comparison of survival curves by using the log-rank test shows that significant differences in survival exist between subjects treated with VT placement and the control sample $(\mathrm{p}=0.001)$.

Conclusions. Our long-term follow-up confirms that VT placement is an effective and safe management option in intractable definite MD, especially in the elderly or in those refusing more invasive treatments.

KEY WORDS: Ménière, therapy, vertigo attacks, ventilation tube

\section{RIASSUNTO}

Obiettivo. Il trattamento della malattia di Ménière (MD) mira a prevenire gravità e frequenza delle crisi di vertigine. Lo studio ha valutato l'efficacia del posizionamento del tubicino di ventilazione (VT) trans-timpanico nel controllo delle vertigini nei pazienti affetti da MD non responsivi alla terapia medica standard.

Metodi. 76 pazienti con diagnosi di MD definita non responsivi alla terapia medica sono stati trattati con posizionamento del VT presso l'UOC ORL dell'Ospedale del Mare, Napoli, Italia, con un follow-up di 3 anni.

Risultati. Il posizionamento del VT si è dimostrato efficace nel controllare le crisi di vertigine nel 61,8\% dei pazienti. Nel gruppo controllo, sottoposto alla sola terapia preventiva standard (SPC), tutti i pazienti hanno riportato persistenza di crisi di vertigine ricorrente durante l'intero periodo di studio. Il confronto delle curve di sopravvivenza mediante logrank test ha evidenziato differenze statisticamente significative nella sopravvivenza tra $i$ soggetti trattati con VT e il campione di controllo $(p=0,001)$.

Conclusioni. I nostri risultati confermano che tale procedura può rappresentare il trattamento di scelta nella gestione efficace e sicura di tali soggetti, specialmente se anziani o che rifiutino trattamenti più invasivi.

PAROLE CHIAVE: Ménière, terapia, crisi di vertigine, tubicino di ventilazione
Received: May 15, 2021

Accepted: June 18, 2021

Correspondence

Vincenzo Marcelli

via Difesa 102, 84043 Agropoli (SA), Italy

E-mail: vincenzo.marcelli@ hotmail.it

Funding

None.

Conflict of interest

The Authors declare no conflict of interest.

\begin{abstract}
How to cite this article: Marcelli V, Spadera L, De Bernardo E, et al. Symptom improvement after transtympanic tube placement in Ménière's disease: preliminary observations. Acta Otorhinolaryngol Ital 2021;41:467-473. https://doi. org/10.14639/0392-100X-N1705
\end{abstract}

(c) Società Italiana di Otorinolaringoiatria e Chirurgia Cervico-Facciale

\section{cc) (i)}

This is an open access article distributed in accordance with the CC-BY-NC-ND (Creative Commons Attribution-NonCommercial-NoDerivatives 4.0 International) license. The article can be used by giving appropriate credit and mentioning the license, but only for non-commercial purposes and only in the original version. For further information: https:// creativecommons.org/licenses/by-nc-nd/4.0/deed.en 


\section{Introduction}

Several studies reported improving symptoms in patients with Ménière's disease (MD) ${ }^{1-5}$ and an inhibiting effect on the development of endolymphatic hydrops ${ }^{6}$ by transtympanic ventilation tube (VT) placement.

Tumarkin in $1966{ }^{1}$ suggested that Eustachian tube obstruction may in some cases start a chain of events leading to $\mathrm{MD}$, and insertion of a grommet may lead to the arrest of this course of events or even to its reversal; in his paper, he came to the suggestive conclusion that: "brings us in headon conflict with the widely accepted belief that MD is purely and exclusively an inner-ear syndrome". While doubting the long-term results, rather smaller than with the other more destructive surgical treatments, in 1969 Lall ${ }^{2}$ wrote that "the relative ease, speed and safety of this procedure are important factors and suggest that it may be worthwhile to try the grommet operation as an initial step in surgical management". In 1988, Montandon et al. ${ }^{3}$ report that "the insertion of a transtympanic ventilation tube prevented the occurrence of vertiginous attack in $82 \%$ of a series of 28 patients suffering from typical Ménière syndrome with incapacitating vertigo resistant to medical treatment". With a more limited sample, Sugawara et al. ${ }^{4}$ also concluded that "this treatment might represent a short-term effect for the reduction of persistent vertigo in some patients with MD and so it might become a treatment option because of its simple and less-invasive procedures". On the other hand, in 2008 Dornhoffer and King ${ }^{5}$ demonstrate that the use of the Meniett device, a small, portable, low-pressure pulse generator, "may be used to provide longer-term reduction of vestibular symptoms in patients with MD". Finally, Kimura and Hutta ${ }^{6}$ in 1997 demonstrated that "middle ear ventilation procedures mechanism significantly reduced the subsequent development of endolymphatic hydrops" and that "the inhibition of hydrops was presumed to be due to pressure release into the middle ear and/or improved oxygenation of the middle and inner ears. Findings suggest the possible merit of a tympanostomy as a treatment for MD in carefully selected patients refractory to medical management".

Although the aetiology of MD is not fully understood, the publications mentioned above are based on the fact that pressure equalisation disorders within the compartments of the inner ear are believed to play a major role in pathophysiology ${ }^{7}$. External pressure has been shown to have an influence on the inner ear pressure ${ }^{8}$, modulating cochlear and vestibular hair cell function ${ }^{9}$. Under certain conditions, middle ear pressure alterations might trigger the triad of symptoms by evoking pressure disturbances in the inner ear.
Despite these interesting and promising premises, none of these methods has ever entered the routine treatment of MD refractory to drug therapy. The reasons can be attributed, for example, to the small number of patients subjected to this treatment, to the limited follow-up of these patients and to the hypothetical side effects of the method (in particular, predisposition to middle ear infections).

On this basis, we thought that our patients who are refractory to therapy could be treated with transtympanic ventilation tube placement to provide a release of middle ear pressure and to prevent externally provoked inner ear pressure changes, before proceeding with more invasive treatments. On this basis, we decided to recruit a significant number of patients refractory to therapy, to treat them with transtympanic ventilation tube placement to provide a release of middle ear pressure and to prevent externally provoked inner ear pressure changes and perform long follow-up, before proceeding with more invasive treatments.

\section{Materials and methods}

This is a prospective study from January 2017 to December 2019 including 76 outpatients who were seen in clinical consultation at the Department of Otolaryngology Head and Neck Surgery, "Ospedale del Mare" Hospital, Naples, Italy, with a clinical diagnosis of unilateral definite MD, according to the AAO- HNS criteria ${ }^{10}$. We recruited 76 patients (26 males, 50 females) with no response to medical therapy for at least 6 months (Tab. I). All patients, aged from 37 to 74 years (mean age 51 years), had been suffering MD for a pre-operative period ranging from 9 to 34 months. The affected ear was the left in 32 patients $(42.1 \%)$ and the right in 44 patients (57.9\%). Exclusion criteria were history of inflammatory middle ear disease, middle ear surgery, vestibular migraine, according to the updated diagnostic criteria ${ }^{11}$, high-resolution CT scanning abnormality

Table I. Intractable MD patient demographics.

\begin{tabular}{lc} 
& Pre-operative data \\
Total sample 8 (n.) & 76 \\
Sex (M:F) & $0.52: 1$ \\
Average age (yrs)^ & $51 \pm 9$ \\
Ear side (L:R) & $0.73: 1$ \\
V-HIT n. (\%) of pts with & \\
$\quad$ hypofunction* & $42(55.3)$ \\
$\quad$ hyperfunction* & $24(31.6)$ \\
$\quad$ normal function* & $10(13.1)$ \\
Pure tone average (dBHL)^ & $33.5 \pm 3.9$ \\
\hline${ }^{\wedge}$ Data are presented as the means \pm standard deviation.* Data refer to the affected ear. \\
MD: Ménière's disease; M: male; F: female; L: left; R: right; yrs: years.
\end{tabular}


of the temporal bone and 1.5 MRI abnormality of the brain. All patients had undergone our routine preventive therapy protocol (standard preventive care, SPC) for six months with any success, as follows:

- hyper hydric (two litres of water per day) and low in sodium (<1500 mg/day) diet;

- betahistine $24 \mathrm{mg}$ orally twice a day;

- SPC flakes 1 gram per kg per day;

- corticosteroid cycles for 8-12 days;

- diuretic, glycerol phleboclysis at 10\%, 500 cc slow drop, according to the frequency of vertigo.

Given the ineffectiveness of this protocol, all patients were subjected to the insertion of Shepard-type ventilation tube (VT) on the affected ear under microscopic control and local anaesthesia following audiological and vestibular revaluation. However, the entire study sample continued the therapy provided by our protocol for the two months following the surgical procedure.

The pre-operative vestibular evaluation was performed with head impulse test (vHIT) ("ICS Impulse" system; GN Otometrics, http://www.icsimpulse.com.): the patient was asked to stare at an earth-fixed target (3-cm diameter spot located $1.5 \mathrm{~m}$ in front), then 20 horizontal impulses $\left(10^{\circ}\right.$ $20^{\circ}$ amplitude) were randomly administered for each side. A gain of vestibulo-oculomotor reflex (VOR) equal to or lower than 0.79 and/or an asymmetry index (AI) between the right and left sides greater than $25 \%$ were assumed as pathological.

The audiological assessment included otomicroscopy, pure tone audiometry by air and bone conduction, tympanometry and acoustic reflex threshold.

The treatment outcomes, vertigo and hearing, were evaluated according to AAO-HNS criteria ${ }^{12}$.

The frequency of vertigo attacks experienced during the 6 months before treatment was compared with the number of attacks experienced between 6 months and 12 months (1-year follow-up), between 18 and 24 months (2-year follow-up), and between 30 and 36 months (3-year follow-up) after treatment. In order to express the effect of treatment on vertigo attacks, a numeric value was calculated as here: the average number of definitive attacks per month after ventilation tube placement was divided by the number that occurred prior to ventilation tube placement. Control of vertigo, as determined by the numeric value, was categorised as follows: $0=\mathrm{A}$, complete control; $1-41=\mathrm{B}$, substantial control; 41-80 = C, limited control; 81-120 = D, insignificant control; $>120=\mathrm{E}$, worse (poor) control; F, secondary treatment initiated because of vertigo-related disability.

The patient was always free to present for immediate evaluation in the event vestibular symptoms recur.

In order to better evaluate the clinical impact of VT place- ment on vertigo control, we also monitored a control sample of 9 patients (average age 54.3 years; 5 women and 4 males) who refused the surgical procedure and continued with SPC only.

To assess the changes of the hearing threshold, we considered the average of bone conduction in pure tone audiogram of $0.25,0.5,1$ and $2 \mathrm{kHz}$. Hearing change (PTA) defined as improved (gain of more than $10 \mathrm{~dB}$ ), unchanged $( \pm 10 \mathrm{~dB})$ or worse (loss of more than $10 \mathrm{~dB}$ ) was considered clinically significant and was evaluated 7 days after surgery and once every 6 months for 3 years. All patients were free to present for immediate evaluation in the event of sudden changes in the hearing threshold.

The study protocol adheres to the principles outlined in the Declaration of Helsinki.

\section{Statistical analyses}

We used Kaplan-Meier time-to-event methods to quantify the percentages of subjects who would have adequate control of their vertigo using a particular definition of "failure". For all patients, we defined failure as requiring intratympanic gentamicin (IT) injections to control vertigo or dropped out of the study for any reason. Time to failure is measured in months, and patients were followed over a period of up to $27.2 \pm 13.5$ months on average (ranging from 1 to 36 months). Data were analysed using statistical packages for social sciences (SPSS), version 26 (SPSS Inc., Chicago, IL, USA).

\section{Results}

\section{Otological conditions}

Medical history did not show any previous pathologies affecting the middle ear, and otomicroscopy was normal in all patients. The tympanogram showed normal compliance of the tympanic membrane and the middle ear compartment (type A tympanogram) and in most patients acoustic reflexes were present and suggestive of the presence of recruitment.

\section{Vertigo control}

Before the insertion of the VT, 42 patients (55.3\%) presented vestibular hypofunction of the affected ear (at least one semicircular canal presented a deficit of the dynamic gain of the VOR evaluated with the vHIT), 24 patients (31.6\%) showed normal vestibular function of the affected ear and 10 patients $(13.1 \%)$ showed a vestibular hyperfunction of the affected ear (at least one semicircular canal presented a dynamic gain of the VOR above the norm evaluated with the vHIT) (Tab. I). 


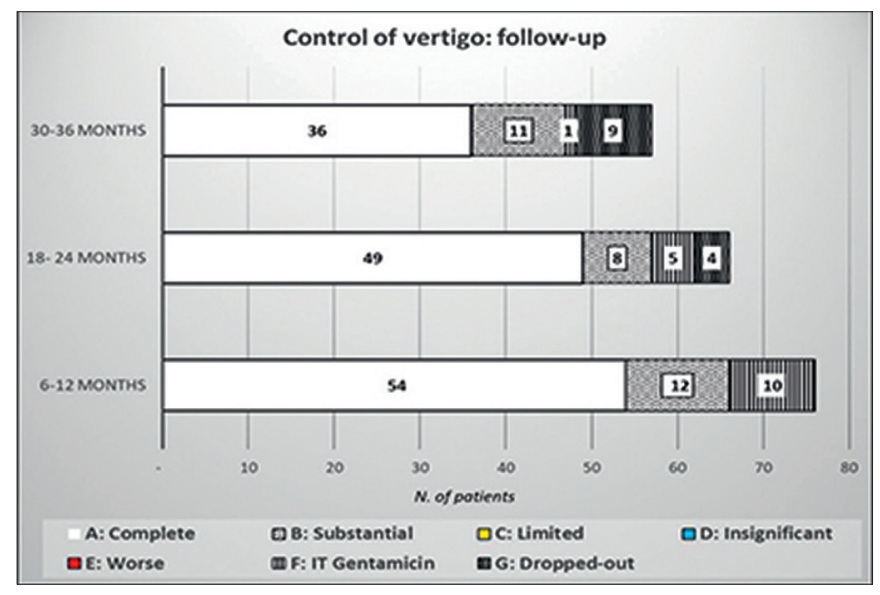

Figure 1. Control of vertigo attacks following ventilation tube placement according to AAO-HNS criteria: short-, medium-, and long-term results.

Over the long term, VT placement was effective in controlling vertigo sufficiently to avoid IT gentamicin treatment in 47 of 76 patients $(61.8 \%)$. More specifically, at the end of 36-month follow-up, 36 patients (47.3\%) had complete (Category A) vertigo control, with an additional $14.5 \%(\mathrm{~N}=11)$ achieving substantial (Category $\mathrm{B})$ control (Fig. 1). The remaining $21.0 \%$ of 76 patients required IT gentamicin injections to treat recurrent vertigo at an average of 10.6 \pm 9.5 months (range: $2-30$ months). In the control group treated with SPC alone, all patients continued to experience recurrent vertigo over the entire study period, but only 3 accepted to receive IT gentamicin treatment with subsequent symptoms relief (Fig. 2).

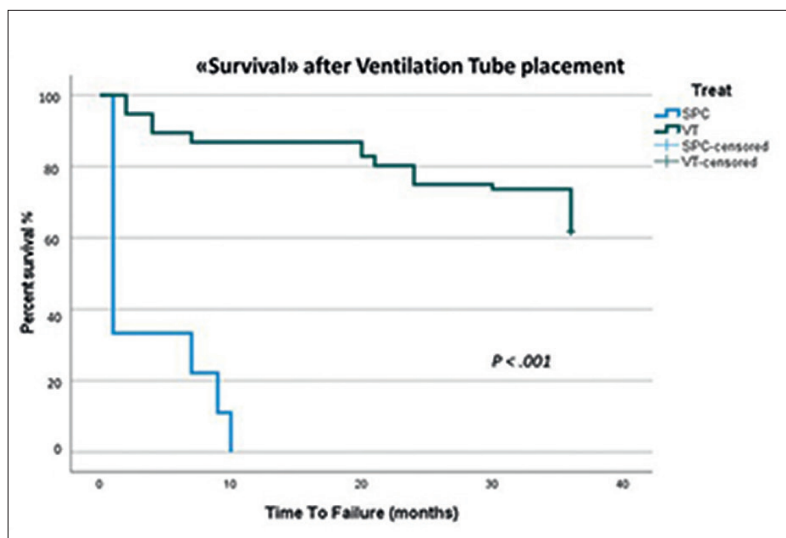

SPC: Standard Preventive Care; VT: Ventilation tube.

Figure 2. Kaplan-Meier "survival" plot after VT placement. The green curve indicates the percentage of patients remaining on VT for vertigo control over time after its insertion. The lowermost blue curve indicates survival following SPC alone. Failure is defined as requiring IT gentamicin treatment for vertigo control and as dropped out of the study.
Comparison of survival curves by log-rank test showed that statistically significant differences in survival exist between subjects treated with VT placement and patients receiving SPC alone (control sample) ( $p=.001)$ (Fig. 2). The overall drop-out rate was $17.2 \%$.

More specifically, at an average of 5 months after insertion of the VT, 10 patients of 76 (13.1\% of the initial sample) showed inadequate control of symptoms and required IT gentamicin administration, which led to vertigo control.

At 12 months after treatment, the sample consisted of 66 patients. 54 patients ( $73.7 \%$ of the initial sample) had complete control of vertigo (Category A) and 12 patients (15.8\%) substantial control (Category B). In 7 patients of both categories (9.2\%), 5 of Category A and 2 of Category $\mathrm{B}$, vertigo attacks reappeared on an average of 8 months after the application of the VT. At the control, the VT was blocked and the symptoms disappeared after its cleaning.

At 24 months, 4 patients of 66 (5.3\% of the initial sample) were no longer present: 3 patients did not show up for follow-up at 18 months and 1 for follow-up at 24 months.

At an average of 17 months after insertion of the VT, 5 patients of $62(6.6 \%)$ showed the reappearance of symptoms and after 4 months on average underwent IT gentamicin treatment, which led to control of the vertigo.

57 patients $(75.0 \%)$ still showed Category A or B symptomatology $(A=49,64.5 \% ; B=8,10.5 \%)$. In 11 patients of these two categories $(14.5 \%, 8$ patients of Category A and 3 of Category B) vertigo attacks reappeared on average at 17 months after VT placement. In 3 patients, the VT presented an occlusion while in 8 patients it spontaneously fell out. The symptoms disappeared after cleaning the tube and positioning a new one.

At 36 months, 9 patients of $57(11.8 \%)$ were no longer present. 3 did not show up for follow-up at 30 months and the other 6 for follow-up at 36 months.

At 28 months after VT placement, only 1 patient of 57 $(1.3 \%)$ showed reappearance of symptoms and after 2 months, received IT gentamicin administration, which led to control of the vertigo.

Complete vertigo control (Category A) was achieved in 36 patients $(47.4 \%)$ and substantial control (Category B) was accomplished in 11 patients (14.5\%). These patients observed a hyper hydric and low-sodium diet and only in very rare cases was it necessary to resort to symptomatic or preventive drugs.

A more detailed description of the data is shown in Table II. As for the control sample, 3 patients (including a fireman) of $9(33.3 \%)$ decided to undergo IT gentamicin 8 months on average after starting therapy; all were no longer dizzy. The remaining 6 patients $(66.7 \%)$ continued not to respond to routine therapy. 
Table II. Outcomes of VT placement.

\begin{tabular}{lccc} 
Patients $(\mathrm{n}=\mathbf{7 6})$ & 1-year follow-up & 2-year follow-up & 3-year follow-up \\
& $\mathbf{6 - 1 2}$ months & 18-24 months & 36 -36 months \\
Category A & $54(73.7 \%)$ & $49(64.5 \%)$ & $11(14.5 \%)$ \\
Category B & $12(15.8 \%)$ & $8(10.5 \%)$ & $1(1.3 \%)$ \\
IT gentamicin & $10(13.1 \%)$ & $5(6.6 \%)$ & $9(11.8 \%)$ \\
Drop-out & $0(0.0 \%)$ & $4(5.3 \%)$ & $57(75.0 \%)$ \\
Total & $76(100 \%)$ & $66(86.8 \%)$ & \\
\hline
\end{tabular}

IT: intratympanic; VT: ventilation tube.

\section{Changes in hearing}

At 6-12 months after treatment, there was no hearing change in any patient (Fig. 3). At 18-24 months after treatment, hearing was unchanged in $51(89.5 \%)$ of 57 patients and was worse in the remaining $6(10.5 \%)$. At $30-36$ months of treatment, hearing was unchanged in $32(68.1 \%)$ of 47 patients and was worse in 15 (31.9\%). There were no patients who showed improved hearing levels.

\section{Tinnitus and fullness}

In none of the treated patients was there significant reduction in the perception of tinnitus, probably a sign of a chronic and clearly irreversible degeneration of the hair cells and a mechanical distortion of the transduction mechanisms. On the other hand, $31 \%$ of patients (13 of 42 patients) reported at least partial reduction in fullness, a phenomenon attributed to the reduction of the pressure load on the inner ear guaranteed by VT and to a more general improvement in the homeostasis of the inner ear.

\section{Adverse events}

In the VT group, adverse events occurred in 24 cases (31.6\%), with VT blockage being the most common event

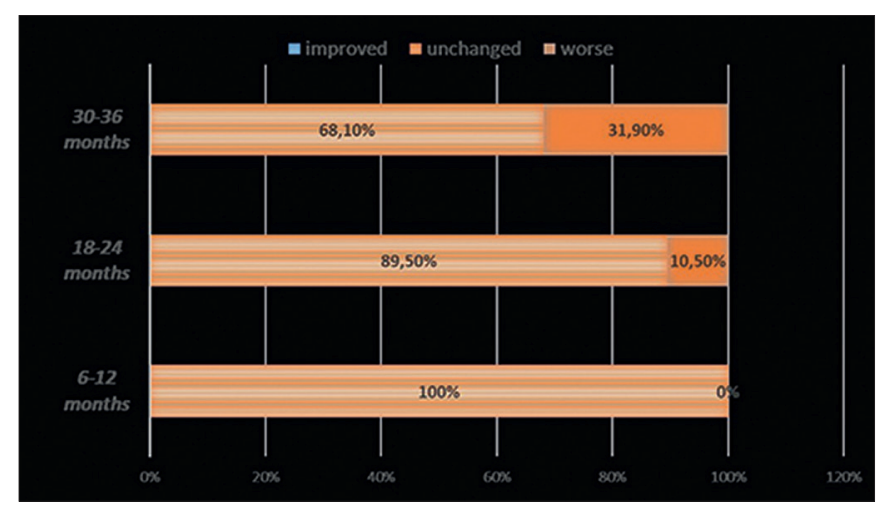

Figure 3. Changes in hearing level following ventilation tube placement: short- medium- and long-term results. Patients dropped out of the study or underwent secondary treatment with IT gentamicin were excluded.
(41.7\%), which was resolved by cleaning in all cases. Six patients $(25.0 \%)$ had to follow local therapy following inflammation and secretion of the treated ear, without any consequence in auditory or vestibular function. In the other patients $(\mathrm{N}=8,33.3 \%)$, the VT spontaneously fell out after 17 months on average and a new ventilation device in the same ear replaced the previous one in all cases.

At present, follow-up is still active and we are still enrolling patients.

\section{Patient compliance}

Despite the inevitable limitations caused by VT (swimming, bathing in the sea, shower), no patient reported being particularly affected by the procedure.

\section{Discussion}

To our knowledge, this is the first work involving a large number of patients with long-term follow-up.

Overall, 36 months after VT placement, $62 \%$ of patients suffering from unilateral definite MD not responding to medical therapy had excellent symptomatic control, without negative effects on the hearing threshold and without particular side effects.

The pathophysiological mechanisms underlying these excellent results are still unclear and we believe this could be one of the reasons why this procedure is not commonly performed. Tumarkin ${ }^{1}$ hypothesised that endolymphatic hydrops in MD developed by blockage of the eustachian tube, creating a negative pressure in the middle ear and causing a suction effect on the endolymphatic system in the inner ear with an incompetent cochlear aqueduct. Even if this hypothesis was confirmed by Lall ${ }^{2}$, who reported that $50 \%$ of patients had good symptom control, Cinnamond ${ }^{13}$ and Hall and Brackmann ${ }^{14}$ subsequently considered the hypothesis unfounded and the treatment useless. More recently, Montandon et al. ${ }^{3}$ treated 28 intractable patients with ventilation tubes and showed improvement or a complete remission of vertiginous attacks in 23 patients (82\%), showing that the ears of these patients were sensitive to 
pressure changes, with symptoms improved by proper middle ear ventilation. Interestingly, these authors reported a recurrence of vertigo attacks in $15(53.6 \%)$ patients whose VT became obstructed or extruded and the disappearance of attacks immediately after the reinsertion of a VT. Ogawa et al. ${ }^{15}$ showed similar good results in 15 patients: complete control of vertigo in three patients and substantial control in seven patients at one year, and complete control in seven patients and substantial control in three patients at two years. These authors also reported recurrence of vertigo attacks when the tube became obstructed or extruded and the disappearance of attacks after the VT was replaced. What are the hypotheses that can explain these encouraging results? Park et al. ${ }^{16}$ showed in a sample of 22 patients that the relief of vertigo cannot be attributed to improved canal-dependent VOR function or to improved saccule function. Kimura and Hutta ${ }^{6}$ demonstrated that middle-ear ventilation procedures significantly reduced experimentally induced endolymphatic hydrops in guinea pigs and the authors attributed this result to pressure release into the middle ear and/or improved oxygenation of the middle and inner ears. In humans, middle ear pressure is positive in the morning and during sleep ${ }^{18,19}$ : VT placement into the middle ear should decrease middle ear pressure to an ambient pressure level ${ }^{20}$ reducing perilymph and endolymph pressures ${ }^{21,22}$ and the development of hydrops. Other possible indications derive from the well-known "alternobaric vertigo" experienced by up to $5 \%$ of otherwise healthy subjects ${ }^{23}$ : the effect of the variation of the atmospheric pressure can clearly be greater in the presence of hydrops and a circulatory insufficiency in the inner ear caused by overpressure is also suggested. On the other hand, the hydropic inner ear may be hypoxic, resulting in increases in endolymphatic pressure ${ }^{24}$. VT placement into the middle ear should improve the oxygen supply to the middle and inner ears and may re-energise and restore some functioning of the stria vascularis and spiral ligament cells and thus play a role in inhibiting the development of endolymphatic hydrops. To confirm this, there is a significant reduction of acute vertiginous attacks in MD patients treated in a hyperbaric oxygen pressure chamber supposedly due to an increase in the oxygen tension of endolymph, with improved endolymph secretion and absorption secondary to the restoration of $\mathrm{Na}+/ \mathrm{K}+$ pumps in the inner ear ${ }^{25}$. Fujita et al. ${ }^{17}$ believe that the VT acts indirectly on the inner ear and is responsible for suppressing changes in middle ear pressure rather than ventilation.

Despite these premises, the significant data that emerges from our work is that since the beginning of the study $62 \%$ of the sample had complete or substantial control of symptoms. Clearly, we must not forget a possible placebo effect, which is well known in the treatment of MD. However, in our work, we believe that we can definitively exclude it: patients who spontaneously returned to our observation due to the reappearance of the vertiginous syndrome could not have been aware that the VT had been occluded or had been extruded, as later demonstrated during the check-up.

\section{Limitations and further research}

The limitations of our study are represented by the limited number of patients and by the follow-up which, despite having reached three years, cannot yet guarantee a very long-term efficacy, considering that the disease has phases of long spontaneous remissions.

Our hope is that our work will be continued and carried on by other centres as well, to increase the number of patients treated, evaluate the results and allow longer follow-up. In this way, it will be possible to better clarify aspects of the pathophysiology of MD and confirm the role of pressure equalisation within the compartments of the inner ear.

\section{Conclusions}

The large number of patients with long-term follow up allow us to consider the results obtained as particularly reliable. We believe that VT placement represents an effective and safe management option for intractable MD and we consider it as a first choice therapy, especially in patients who do not want to undergo more invasive treatments.

\section{Acknowledgements}

The author would like to thank Elisabetta Cristiano, Antonio Giannone and Domenico D’Errico for their friendship and cooperation.

\section{References}

1 Tumarkin A. Thoughts on the treatment of labyrinthopathy. J Laryngol Otol 1966;80:1041-1053. https://doi.org/10.1017/ s0022215100066366

2 Lall M. Ménière's disease and the grommet [a survey of its therapeutic effects]. J Laryngol Otol 1969;83:787-791. https://doi.org/10.1017/ s002221510007095x

3 Montandon P, Guillemin P, Hausler R. Prevention of vertigo in Menière's syndrome by means of transtympanic ventilation tubes. ORL J Otorhinolaryngol Relat Spec 1988;50:377-381. https://doi. org/10.1159/000276016

4 Sugawara K, Kitamura K, Ishida T, et al. Insertion of tympanic ventilation tubes as a treating modality for patients with Menière's disease: a short- and long-term follow-up study in seven cases. Auris Nasus Larynx 2003;30:25-28. https://doi.org/10.1016/s0385-8146(02)00105-0

5 Dornhoffer JL, King D. The effect of the Meniett device in patients with Ménière's disease: long-term results. Otol Neurotol 2008;29:868874. https://doi.org/10.1097/MAO.0b013e318182025a 
6 Kimura RS, Hutta J. Inhibition of experimentally induced endolymphatic hydrops by middle ear ventilation. Eur Arch Otorhinolaryngol 1997;254:213-218. https://doi.org/10.1007/BF00874091

7 Valk WL, Wit HP, Albers FW. Evaluation of cochlear function in an acute endolymphatic hydrops model in the guinea pig by measuring low-level DPOAEs. Hear Res 2004;192:47-56. https://doi. org/10.1016/j.heares.2003.12.021

8 Feijen RA, Segenhout JM, Albers FWJ, et al. Change of guinea pig inner ear pressure by square wave middle ear cavity pressure variation. Acta Otolaryngol 2002;122:138-145. https://doi. org/10.1080/00016480252814135

9 Duwel P, Jungling E, Westhofen M, et al. Potassium currents in vestibular type II hair cells activated by hydrostatic pressure. Neuroscience 2003;116:963-972. https://doi.org/10.1016/s0306-4522(02)00776-5

10 Lopez-Escamez JA, Carey J, Chung WO, et al. Diagnostic criteria for Ménière's disease. J Vestib Res 2015;25:1-7. https://doi.org/10.3233/ VES-150549

11 Lempert T, Olesen J, Furman J, et al. Vestibular migraine: diagnostic criteria. J Vestib Res 2012;22:167-172. https://doi.org/10.3233/ VES-2012-0453

12 Committee on Hearing and Equilibrium. Committee on Hearing and Equilibrium guidelines for the diagnosis and evaluation of therapy in Menière's disease. Otolaryngol Head Neck Surg 1995;1138:181-185. https://doi.org/10.1016/S0194-5998(95)70102-8

13 Cinnamond MJ. Eustachian tube function in Menière's disease. J Laryngol Otol 1975;89:57-61. https://doi.org/10.1017/ S0022215100080075

14 Hall M, Brackmann DE. Eustachian tube blockage and Ménière's disease. Arch Otolaryngol 1977;103:355-357. https://doi.org/10.1001/ archotol.1977.00780230077012

15 Ogawa Y, Otsuka K, Hagiwara A, et al. Clinical study of tympanostomy tube placement for patients with intractable Ménière's disease. J Laryngol Otol 2015;129:120-125. https://doi.org/10.1017/ S0022215115000079
16 Park JJ, Chen YS, Westhofen M. Ménière's disease and middle ear pressure: vestibular function after transtympanic tube placement. Acta Otolaryngol 2009;129:1408-1413. https://doi. org/0.3109/00016480902791678

17 Fujita N, Yamanaka T, Nario K, et al. Long-term follow-up of eardrum ventilation tube placement for intractable cases of Ménière's disease. Journal of Japan Society for Head and Neck Surgery 2016;25:333337. https://doi.org/10.5106/jjshns.25.333

18 Hergils L, Magnuson B. Middle ear pressure under basal conditions. Arch Otolaryngol Head Neck Surg 1987;113:829-832. https://doi. org/10.1001/archotol.1987.01860080035011

19 Shinkawa H, Okitsu T, Yusa T, et al. Positive intratympanic pressure in the morning and its etiology. Acta Otolaryngol (Stockh) 1987;435(Suppl):107-111. https://doi.org/10.3109/00016488709107358

20 Cantekin EI, Doyle WJ, Phillips DC, et al. Gas absorption in the middle ear. Ann Otol Rhinol Laryngol 1980;89(Suppl):71-75. https://doi. org/10.1177/00034894800890s320

21 Nakashima T, Watanabe Y, Yanagita N. The effect of round window membrane rupture on endolymphatic and perilymphatic pressures. Arch Otorhinolaryngol 1987;244:236-240. https://doi.org/10.1007/ BF00455312

22 Nishihara S, Gyo K, Yanagihara N. Transmission of change in the atmospheric pressure of the external ear to the perilymph. Am J Otol 1992;13:364-368.

23 Yoshida M, Lowry LD. Hydrostatic pressure measurement of endolymph and perilymph in the guinea pig cochlea. Am J Otolaryngol 1984;5:159-165. https://doi.org/10.1016/s0196-0709(84)80007-1.

24 Ingelstedt $\mathrm{S}$, Ivarsson A, Tjernström Ö. Vertigo due to relative overpressure in the middle ear: an experimental study in man. Acta Oto-Laryngologica 1974;78:1-14. https://doi.org/10.3109/00016487409126319

25 Fattori B, Ghilardi PL, Casani A, et al. Hyperbaric oxygenation therapy in Ménière's disease. In: Filipo R, Barbara M, editors. Ménière's disease: perspectives in the 90's. Amsterdam: Kugler; 1994. pp. 493-496. 